\title{
The Float Park: A New Tool for a Cost-Effective Collection of Lagrangian Time Series with Dual Release RAFOS Floats
}

\author{
Walter Zenk, ANdreas Pinck, And Sylvia Becker \\ Institut für Meereskunde an der Universität Kiel, Kiel, Germany \\ PIERRE TILLIER \\ SeaScan, Inc., Falmouth, Massachusetts
}

(Manuscript received 12 November 1998, in final form 14 December 1999)

\begin{abstract}
The World Ocean Circulation Experiment has established Lagrangian observations with neutrally buoyant floats as a routine tool in the study of deep-sea currents. Here a novel variant of the well-proven RAFOS concept for seeding floats at locations where they can be triggered on a timed basis is introduced. This cost-effective method obviates the need to revisit sites with a high-priced research vessel each time floats are to be deployed. It enables multiple Lagrangian time series, for example, for the observation of intermediate point sources of water masses, which are independent but have identical start points. This can be done even in environmentally challenging regions such as below the ice. The successfully tested autonomous float park concept does not rely on a release carousel moored on the seafloor. Instead, a second release was added to the standard RAFOS float for optional delay of regular drift missions. A float park can easily be installed by a conductivity-temperaturedepth recorder system with a slightly modified rosette sampler.
\end{abstract}

\section{Introduction}

For the observation of ocean currents in certain limited regions we propose a new variant of the Ranging and Fixing of Sound (RAFOS) technology (Rossby et al. 1986). This Lagrangian technique for the observation of intermediate and deep ocean currents relies on the propagation of acoustic signals between moored sound sources and freely drifting RAFOS floats. A minimum of two sound sources are required. They transmit typically one sound package at $260 \mathrm{~Hz}$ of 80 -s duration at fixed time windows. These signals propagate in all directions. Transmission times of all sources belonging to an array are delayed by $30 \mathrm{~min}$. This allows a sound package at an averaged speed velocity of $1.5 \mathrm{~km} \mathrm{~s}^{-1}$ to travel about $2700 \mathrm{~km}$ before the next package of an associate source is emitted. Adjacent listening windows of the RAFOS receivers enable the determination of arrival times from the different sources. The float's microprocessor correlates the incoming frequency modulated (FM) signal and stores the highest and secondhighest correlation and their times of arrival. The latter

Corresponding author address: Walter Zenk, Institut für Meereskunde an der Universität Kiel, Düsternbrooker Weg 20, D-24105 Kiel, Germany.

E-mail: wzenk@ifm.uni-kiel.de recordings represent the base for later triangulation of acoustic radii resulting in trajectories of our roving floats. After the floats have finished their preprogrammed underwater mission, they drop their ballast weights, return to the surface, and transmit their data via satellite link (Systeme ARGOS).

In this paper we introduce a recently developed and field tested RAFOS float derivative: the dual release float. We call a cluster of moored dual release floats a "float park." A park can sequentially release temporarily moored floats from the sea floor. Because of the compressibility difference between water and the glass housing of floats, they are buoyant while on the seafloor far below their intermediate mission levels. After their initial release has been triggered following a predetermined delay, they ascend to their intended mission depth where they act as Lagrangian current meters like regular RAFOS floats.

\section{Purpose}

The simple idea of a float park (Fig. 1) can be applied when an intentionally delayed start of Lagrangian time series is desirable. Technically this new RAFOS family member will be used in regions with expected unfavorable weather or ice conditions, or where logistical constraints prevent regular seeding of RAFOS floats. For example, the latter scheme was successfully carried 


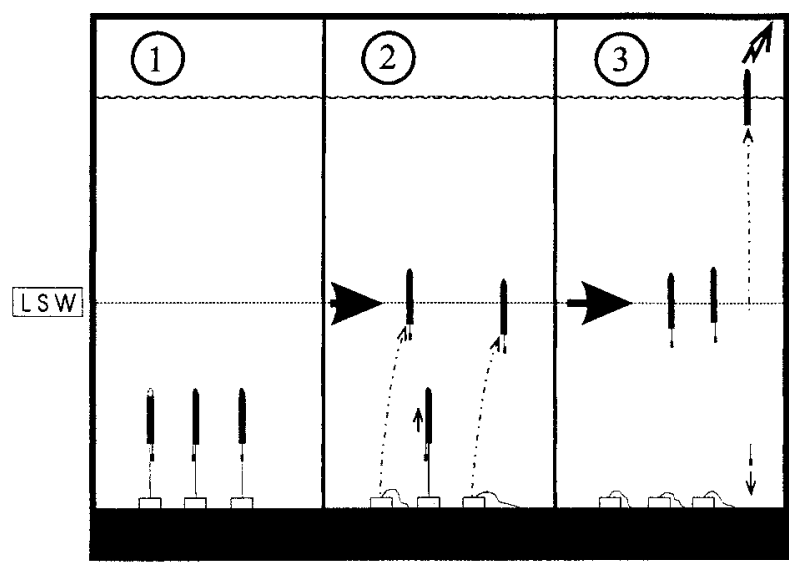

FIG. 1. (1) A float park consists of a number of temporarily moored RAFOS floats. (2) After a predetermined time individual floats depart from their anchors and ascend to their mission depths where they are subsequently advected horizontally. (3) At the end of their mission they drop a ballast weight, return to the sea surface, and transmit their stored data, i.e., typically the daily time-of-arrival signals from moored sound sources, and temperature and pressure data. The first float park was successfully tested east of Charlie Gibbs Fracture Zone (depth $>3500 \mathrm{~m}$ ) in the Northeast Atlantic. Floats monitored the drift of Labrador Sea Water (LSW).

out on a chartered sailing yacht during the Mediterranean Undercurrent Seeding Experiment (AMUSE) in the Gulf of Cadiz between 1993 and 1995 (Hunt et al. 1998). In general, float parks are especially suitable in regions with point sources where spreading of water masses and their subsequent eddy generation and transformation are of major interest (Richardson et al. 2000). The observational result of a float park consists of a collection of float trajectories which all start at the same origin and yield sequential drift estimates from intermediate depths that are representative for certain seasons and regions.

The dual release floats are passive while moored on the seafloor. They hibernate for predetermined times until they wake up for their drift mission. A secondary, but not yet realized, task for dual release floats lies in their capability to act temporarily as monitors on the sea floor (MAFOS) (König et al. 1991). The latter instrument class was developed to improve RAFOS navigation accuracy by enabling corrections for potential long-term clock drifts and erratic jumps in the time base of sound sources.

\section{System description}

The technical realization of the first RAFOS float park was conducted through the cooperation of the Institut für Meereskunde in Kiel, Germany, and SeaScan of Falmouth, Massachusetts. The instruments are a derivative of the float generation built by SeaScan according to the design and specifications evolved by T. Rossby and B. Owens and their teams at the University of Rhode

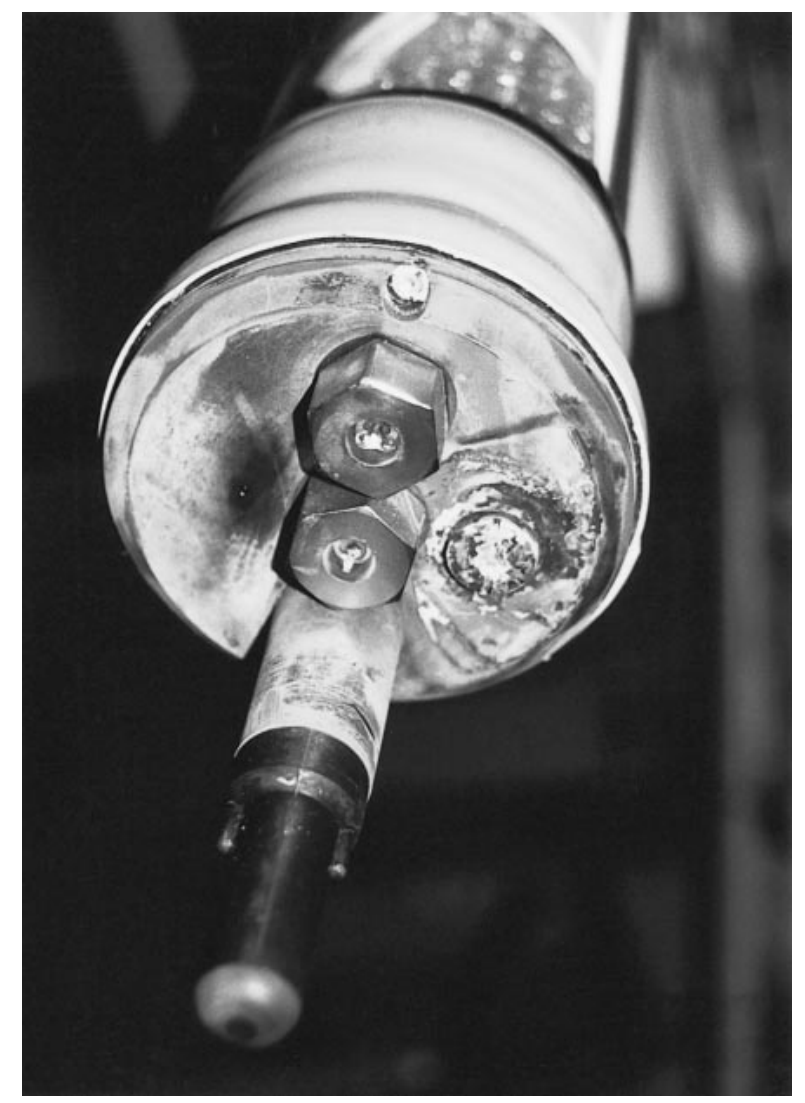

FIG. 2. End plate of dual release float No. 414 after recovery by FS Poseidon. The black hydrophone for the reception of acoustic signals with its extender pipe stuck through the released cylindric ballast weight. The two hexagonal release blocks are displayed at the center of the photograph. On the right-hand side we see the strongly corroded valve screw. The instrument was under water for 15 months.

Island and the Woods Hole Oceanographic Institution. They were part of the World Ocean Circulation Experiment (WOCE) Lagrangian drifter experiment (Zenk 1997). The useful life of the instrument depends on the details of the mission programmed in FORTH. It can typically exceed 18 months.

The float is housed in a borosilicate glass pipe with one end rounded and closed (top) and the other end open. An anodized aluminum end plate closes the lower opening. It supports all the mechanical penetrators such as the pressure port, two hexagonal blocks with burn wires, a vacuum valve, and hydrophone (Fig. 2). All internal components are mounted on a styrene backbone. Starting from top to bottom, there is an ARGOS antenna and transmitter, the electronic boards, and the battery pack.

For the dual release version a second electronic board was added to the standard WOCE FORTH board. Its elementary modules include a single conversion acoustic receiver, power supply, I/O interface, hardware clock, switches for the ARGOS transmitter, electronic burn wires, pressure and temperature circuits, CPU, and 


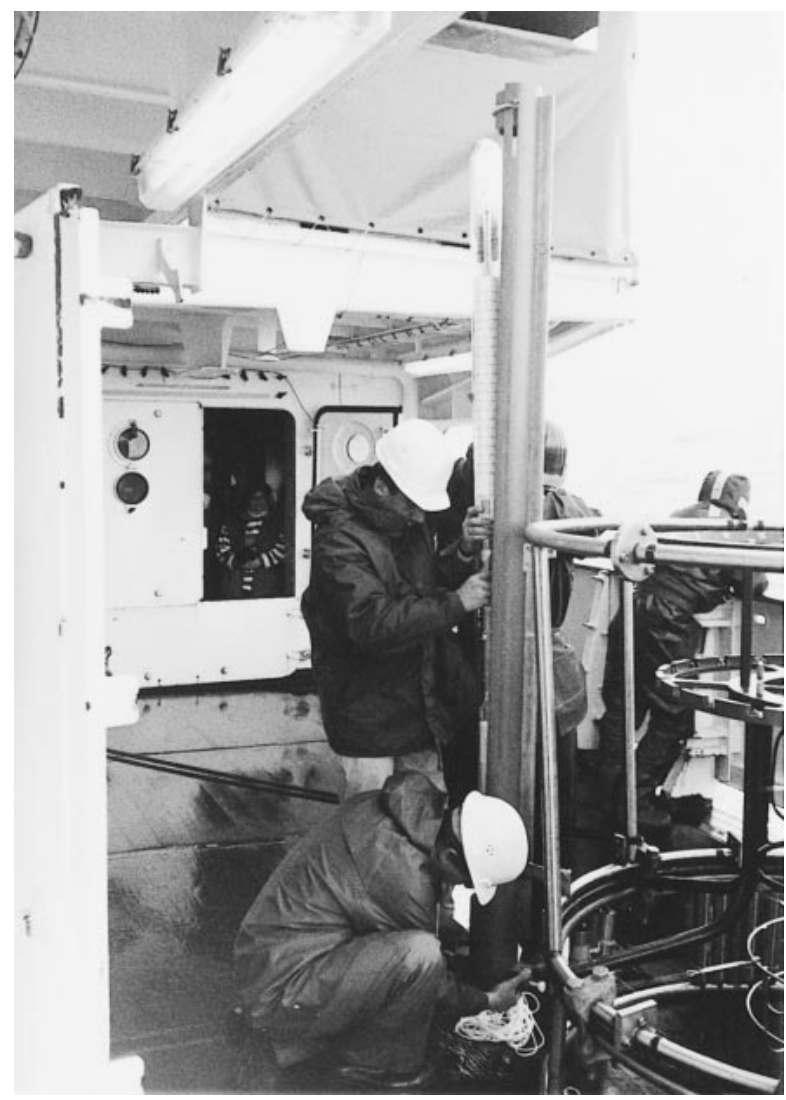

FIG. 3. For a precise and gentle installation of the first float park we constructed a launch apparatus. It is operated by a rosette sampler of a CTD system. During lowering the vertical pipe holds the float to be moored.

memory (16 kB ROM and $32 \mathrm{kB}$ RAM). The available FORTH software had to be extended for the delayed functions. Newly introduced FORTH words include "wire on/off" for servicing the first release block, which separates the moored float from its $12-\mathrm{kg}$ dinghy anchor. RS232 compatible communication with the instrument's processor is established by an optical link directly attached to the glass hull for programming and down-load sessions. In terms of costs the dual release version exceeds its parent by less than $5 \%$.

For a precise and gentle deployment of RAFOS floats with two release blocks we have developed a special launch apparatus. It houses one float and is positioned vertically on a standard rosette sampler with the conductivity-temperature-depth recorder (CTD) lowered from the support ship (Fig. 3). This release apparatus replaces one Niskin bottle. Without any extra communication link the launch release is triggered from the CTD deck unit. Distance from the bottom can be controlled by a pinger that is often part of the CTD system. In our first park we triggered the pipe release successfully $20 \mathrm{~m}$ above the bottom.

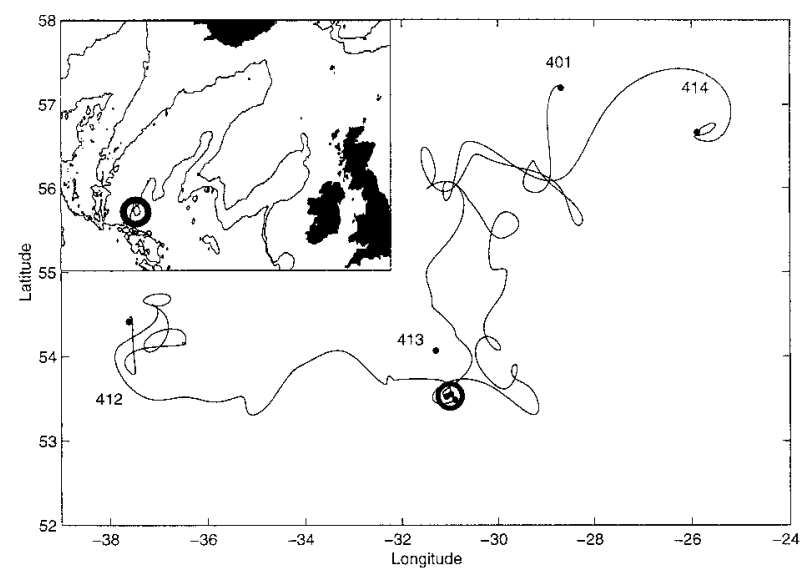

FIG. 4. Charts of the northeastern Atlantic Ocean. Labrador Sea water penetrates through Charlie Gibbs Fracture Zone into the Iceland Basin: $110 \mathrm{~km}$ east of this gap in the Mid-Atlantic Ridge we had installed our first float park (circle). The trajectories of four floats demonstrate the high amount of eddy noise and variability of the mean current in the intermediate water. To avoid unnecessary confusion the fourth trajectory (413), which resembles a random walk regime, was omitted in the figure. All surface locations are labeled by black dots. Before plotting, data were low-pass filtered (cut-off period 10 day) excluding small-scale tracking noise. For further details see Table 1.

\section{A first experiment}

A first RAFOS float park was installed on 28 May 1997 at about $531^{1 / 2} \mathrm{~N}, 31^{\circ} \mathrm{W}$, that is, roughly $110 \mathrm{~km}$ east of Charlie Gibbs Fracture Zone in the North Atlantic (Fig. 4). This region is at the northeastern margin of the subpolar gyre and is of special interest to oceanographers. Its position at the southern tip of the Reykjanes Ridge provides for an intensive exchange of intermediate and deep water masses across the Mid-Atlantic Ridge. Low salinity Labrador Sea water is formed by convection west of Greenland, and spreads east at about 1300-1700-m depth after penetrating the Iceland Basin through the Gibbs Fracture Zone (Sy et al. 1997). Due to their climate relevance, seasonal and interannual changes of the inflow of Labrador Sea Water are of special interest.

It was the aim of our first float park experiment to demonstrate the feasibility of monitoring the circulation of intermediate waters by Lagrangian current meters. Because the relatively low salinity of Labrador Sea water, small variations can have a profound impact on water mass transformations in the Iceland Basin.

The first experiment was started from the FS Meteor. In May 1997 we launched four floats, one standard RAFOS and three dual release floats. Their mission parameters are shown in Table 1. All four instruments performed satisfactorily and returned to the surface at prescribed times. Though we were scheduled to return to the region only a few weeks later in August 1998 after all members of the float park surfaced, we had not originally planned to recover any of our four expendable 


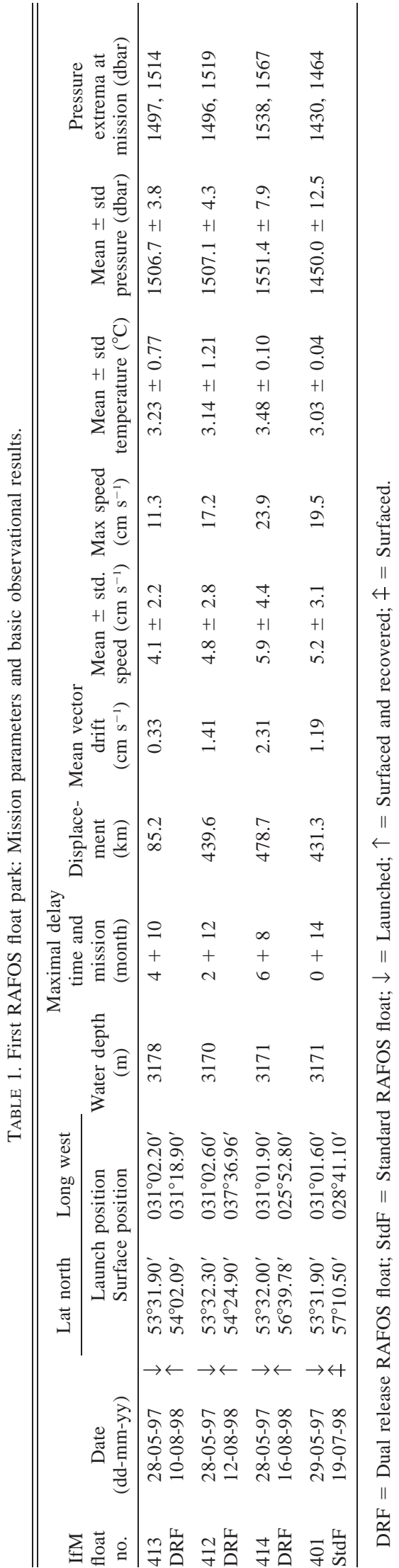

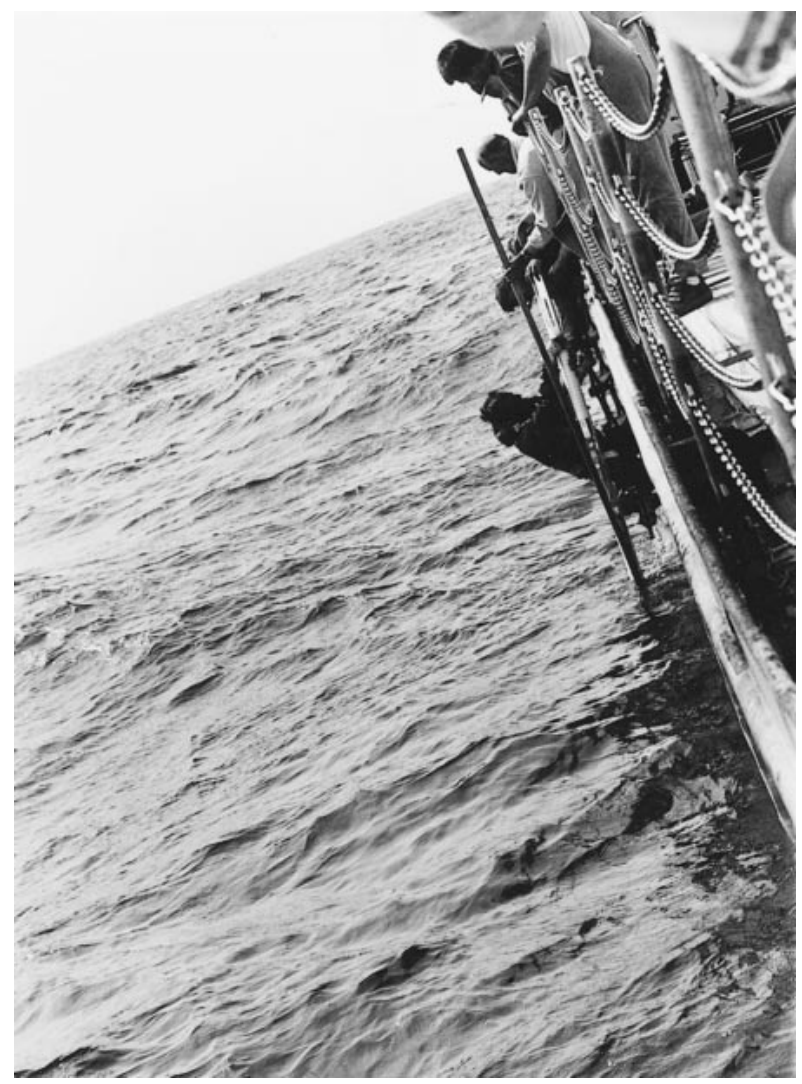

FIG. 5. Although RAFOS floats are built as expendable instruments three surfaced instruments were recovered from board the FS Poseidon. The picture shows a sailor in a survival suit with life line at calm weather conditions. He captured the drifting float from the pilot's ladder and hands it on board where the instrument was warmly welcomed after 15 months in the water. Severe corrosion damage was detected on this float on the valve of the end plate (see Fig. 2).

floats. However, with some coordination and good luck we managed to locate and recover three freely drifting and telemetering floats by a specialized ARGOS receiver (GONIO) on FS Poseidon (Fig. 5). The unexpected retrieval of $75 \%$ of the hardware from the first float park enabled us to examine the impact of corrosion and the long-term behavior of the first prototypes. All mechanical parts worked well. Signs of significant corrosion were observed on the slots of the pressure release valves in the end plate (see Fig. 2).

Overlaid in Fig. 4 are the trajectories from the first park floats. Basically, we expected a predominant easterly flow advecting fresh Labrador Sea Water into the Iceland Basin with superimposed eddy "noise." Even if we assume $100 \mathrm{~km}$ to be a typical correlation scale for the intermediate inflow east of Gibbs Fracture Zone, we cannot detect a coherent spreading of Labrador Sea Water in these trajectories. With the exception of the southwest quadrant, all other flow directions were observed in the float park region. The trajectories of our winter float 414 with its northeastern drift best illustrates the expected flow regime. In contrast, float 412 started 
its mission at mid summer and was advected westward by a counter current into the Irminger Sea. Further observations and the evaluation of simultaneous Eulerian current meter data from just north of Gibbs Fracture Zone will assist us in explaining the peculiar return flow shown by float 412 .

\section{Conclusions}

An instrument type has been built and successfully tested over 15 months that allows the establishment of a Lagrangian time series (cf. Rossby et al. 1995). Depending on scientific objectives, financial resources and accessibility of monitoring sites dual release floats in parks (also called "float farms") can report representative currents and their natural variability. Their trajectories allow to estimate temporal and spatial means and variances.

Since the dual release float is derived from a standard RAFOS float, it constitutes a low-cost, expendable instrument that can be deployed in groups from the seafloor. For its control tasks it utilizes the existing capability of the microprocessor on board the standard float. In fact, it makes any additional apparatus with revolving triggers and separate time releases on the ground superfluous. In principle dual release floats can start their Lagrangian mission from a variety of underwater platforms, that is, a light anchor or a mooring of opportunity. We suggest that this simple new tool will become an integral part of the Global Ocean Observing System presently under discussion or in preparation by a number of bodies in operational oceanography. Float-park data will have the potential of detecting and monitoring climate changes and for understanding oceanic variability over a wide range of timescales in selected ocean regions (OOPC 1998).

Acknowledgments. This work has been supported by the Deutsche Forschungsgemeinschaft, Bonn (SFB 460). We thank the captains and the crews of FS Meteor and Poseidon for their skilled help during deployment and the unforeseen recovery exercises of our first dualrelease floats. We also thank two anonymous reviewers for their valuable suggestions.

\section{REFERENCES}

GOOS Rep 33, 37 pp. [Available from UNESCO.]

Hunt, H. D., C. M. Wooding, C. L. Chandler, and A. S. Bower, 1998: A Mediterranean Undercurrent Seeding Experiment (AMUSE): Part II. Woods Hole Oceanographic Institution Tech. Rep. 9814, 123 pp. [Available from Woods Hole Oceanographic Institution, Woods Hole, MA 02543.]

König, H., K. L. Schultz Tokos, and W. Zenk, 1991: MAFOS: A simple tool for monitoring the performance of RAFOS sound sources in the ocean. J. Atmos. Oceanic Technol., 8, 669-676.

Richardson, P., A. Bower, and W. Zenk, 2000: A census of meddies tracked by floats. Progress in Oceanography, Vol. 45, Pergamon, 209-250.

Rossby, T., D. Dorson, and J. Fontain, 1986: The RAFOS system. J. Atmos. Oceanic Technol., 3, 672-679.

— , G. Siedler, and W. Zenk, 1995: The volunteer observing ship and future ocean monitoring. Bull. Amer. Meteor. Soc., 76, 5-11.

Sy, A., M. Rhein, J. R. N. Lazier, K. P. Koltermann, J. Meincke, A. Putzka, and M. Bersch, 1997: Surprisingly rapid spreading of newly formed intermediate water across the North Atlantic Ocean. Nature, 386, 675-679.

Zenk, W., 1997: North Atlantic anticipates biggest float fleet ever. Int. WOCE Newsl., 27, 32-34. 